\title{
The Efficacy of GeoGebra-Assisted Instruction on Students' Drawing and Interpretations of Linear Functions
}

\author{
Ugorji Iheanachor Ogbonnaya \\ University of Pretoria, Pretoria, South Africa \\ https://orcid.org/0000-0002-6243-5953 \\ Melody Mushipe \\ University of South Africa, Pretoria, South Africa \\ https://orcid.org/0000-0003-4005-898X
}

\begin{abstract}
The purpose of this study was to explore the effectiveness of GeoGebra assisted instruction on students' achievement in drawing graphs of linear functions and interpretation of the representations of linear functions. These aspects of linear functions tend to pose a challenge to many students. The non-equivalent control group pre-testpost-test quasi-experimental research design was used in the study. The sample was 94 Grade 9 students from three secondary schools in a province in South Africa. Two schools formed the control groups and one school was the experimental group. Data were collected using achievement tests. The tests results were analysed using inferential statistics (Kruskal-Wallis and Mann-Whitney U comparison tests) at 0.05 level of significance. Statistically significant differences were found between the groups with respect to drawing and interpretation of linear functions graphs with the experimental group obtaining the highest mean scores. The findings suggest that GeoGebra assisted instruction might be a way of enhancing students' ability to draw the graphs of linear functions and analyse and interpret the representations of linear functions.
\end{abstract}

Keywords: Drawing graphs; Geogebra; interpreting graphs; linear functions; technology

\section{Introduction}

In mathematics, "a linear function is a function $f$ on the real numbers that is given by $f(x)=a x+b$, where $a, b$ are real numbers and $a \neq 0$ " (Marsigit et al., 2011, In Wijayanti, 2018, p. 475). Linear functions can be represented graphically with straight lines (Laridon et al., 2004). Functions are very critical in mathematics education; they are fundamental topics in school mathematics. They are applied in many branches of mathematics and other subjects. Various 
aspects of functions are utilised in real life as a basis of decision-making. For example, in an everyday economic situation, a function may be used to understand how the cost of fuelling a car is related to the quantity of fuel added or how the distance travelled is related to the quantity of petrol used. Today, most statistical data in the media (depicting a relationship between two or more variables) are presented in tables and graphs of which the knowledge of linear functions will help one to make sense of most of the statistical information. Fair grasp of statistical information is a necessary and valuable skill for the socioeconomic wellbeing of an individual and a society at large in the $21^{\text {st }}$ century. Hence, the learning of linear functions is important because it "provides students with their first experience of identifying and interpreting the relationship between two dependent variables" (Pierce, 2005, p.81). According to Pierce, this experience is a significant point of transition in the students' mathematical development.

In the South African school curriculum, linear functions is formally taught in the Grades 7-9. In the Grade 9 mathematics curriculum, students are to "draw linear graphs from given equations and determine the equations of functions from given linear graphs". Besides, students are expected to "analyse and interpret linear functions with special focus on the $x$-intercept and $y$-intercept, and gradient" (Department of Basic Education, 2011, p.26). The representations and interpretations of linear functions seem to be challenging for many students. One possible reason for the students' challenge on this topic could be their inability to relate the various representations of the function.

To support students' learning of some mathematical concepts, many researchers advocate the integration of technology with the teaching of those concepts. Similarly, the South African school curriculum supports the use of available technologies in the teaching of mathematics (Department of Basic Education, 2011).

This study explored the efficacy of GeoGebra assisted instruction on Grade 9 students' drawing of linear functions graphs and interpretations of the representations of linear functions using a non-equivalent control group pretest-post-test quasi-experimental design (Cohen, Manion \& Morrison, 2011), with a sample of 94 Grade 9 students from three secondary schools in a province of South Africa. The background of the study is presented, followed by the research methodology, the findings, discussion of the findings, and the Conclusion and recommendations.

\subsection{Background}

Historically, the use of various forms of technologies (teaching aids and manipulative) has been part of education. In the past few decades, development in technology has significantly influenced teaching and learning (Akcay, 2017; Mueller, Wood, Willoughby, Ross \& Specht, 2008). There is strong evidence in the literature that technology combined with an appropriate teaching approach supports the learning of many school subjects. In mathematics education, the use of technology in teaching could date back to the use of the Abacus. In the recent years, Information, communication and technology (ICT) is found to support the 
teaching and learning of mathematical concepts by enabling the visualisation of some of these concepts and thereby making learning meaningful and joyful to students (Ogbonnaya, 2010; Thambi \& Eu, 2012).

The integration of technology (e.g. GeoGebra) with mathematics teaching agrees with the constructivist theory of learning that learning is an active process; people learn through exploration and active participation in the learning process (Slavin \& Davis, 2006). The integration of technology with teaching and learning mathematics could enable students' active engagement with the learning as they strive to make sense of mathematical concepts using technology. Dynamic geometry software technologies, such as GeoGebra, stimulates students to develop their mathematical argumentation by making conjectures and explore the outcome of their conjectures (Disbudak \& Akyuz, 2019). Exploration with this technological tool leads to reflection and knowledge construction in line with the constructivist perspective of learning.

Many research studies in mathematics education have found the integration of some ICT tools effective in supporting the teaching and learning of some mathematical concepts (Bester \& Brand, 2013; Ogbonnaya \& Mji, 2012; Bray \& Tangney, 2017).

\subsection{Research purpose}

This study explored the effectiveness of GeoGebra assisted instruction on Grade 9 students' learning achievement in linear functions. The research questions addressed are: does GeoGebra assisted linear functions instruction make a statistically significant difference in Grade 9 students' learning achievement in (i) drawing of linear functions graphs? and (ii) interpreting linear functions?

To help answer the research questions the following two hypotheses were tested at 0.05 level of significance: GeoGebra assisted linear functions instruction does not significantly affect Grade 9 students' learning achievement in (i) drawing of linear functions graphs, and (ii) interpreting of linear functions.

\subsection{GeoGebra}

GeoGebra is an interactive mathematics software created by Markus Hohenwarter in 2002. GeoGebra brings together the features of computer algebra systems and dynamic geometry software (Hohenwarter \& Jones, 2007). It is user friendly and multilingual in its menu and commands (https://www.geogebra.org). Zengin, Furkanb and Kutluca (2012) noted that "GeoGebra is a dynamic learning environment that enables its users to create mathematical objects and interact with them. GeoGebra users, ... can model mathematical concepts and the relationships between them" (p. 184). GeoGebra can be used to carry out statistical analysis. Users can create statistical graphs, test hypotheses and simulate real-life situations (Phan-Yamad \& Man, 2018). It can be downloaded for free from the internet. GeoGebra makes it possible for "dynamically linked multiple representations for mathematical objects" (Hohenwarter \& Lavicza, 2009, p.3) in one window as shown in the graphical and algebraic representations of the lines $y=-1.5 x+20$ and $y=x+6$ in Figure 1. This feature makes GeoGebra a powerful tool for learning most mathematics topics. 


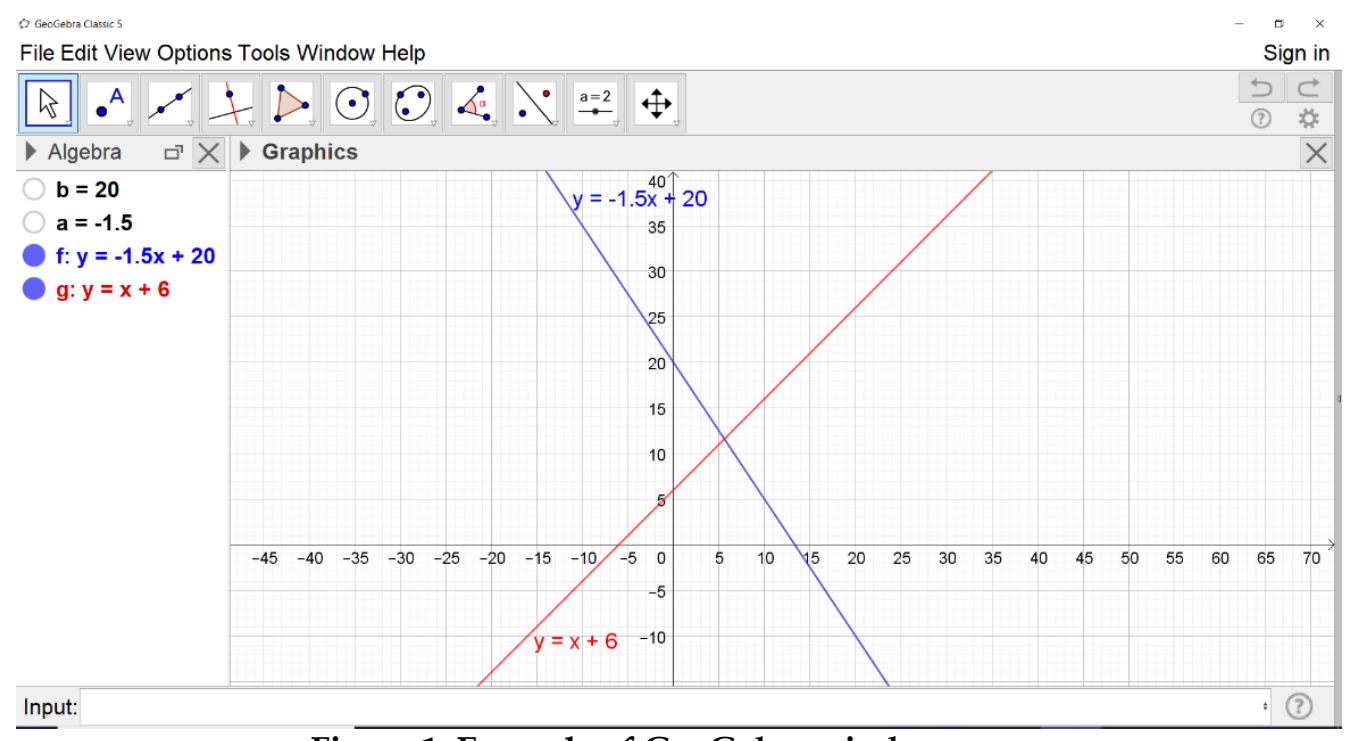

Figure 1: Example of GeoGebra window

Many studies have explored the effectiveness of GeoGebra in teaching some mathematical topics at different levels of education (Aydos, 2015; Granberg \& Olsson, 2015; Takači, Stankov \& Milanovic, 2015; Wassie \& Zergaw, 2018). Most of the studies reported a positive effect of Geogebra on students learning. For example, Arbain and Shukor (2015) studied the impact of GeoGebra on secondary school students' achievement in solving statistics problems in Malaysia. The study found that GeoGebra positively impacted on the students' learning achievement in statistics.

In a quasi-experimental with university students' study in Jordan, Alkhateeb and Al-Duwairi (2019) explored the effects of GeoGebra on the students' learning achievement in geometry. The results show that GeoGebra had a positive effect on the students' achievement. Pjanić and Lidan (2015) studied the influence of GeoGebra on pre-service mathematics teachers' content knowledge of the area of a trapezium, in a university in Turkey. The result of their study showed that the use of GeoGebra applet had a positive effect on the pre-service teachers' knowledge of trapezium.

In Pakistan, Khalil, Farooq, Çakıroğlu, Khalil and Khan (2018), studied the effect of GeoGebra aided instructions on the mathematical achievement of Grade 12 students in Analytic Geometry. The researchers compared the learning achievement of (i) high achievers in the GeoGebra aided instruction class and high achievers in the non-GeoGebra aided instruction class, (ii) low achievers in the GeoGebra aided instruction class, and low achievers in the non-GeoGebra aided instruction class. The results showed that in both the high and low achievers' categories, the students in the GeoGebra aided instruction class significantly achieved better than the students in the non-GeoGebra aided instruction class. Besides, the students of GeoGebra aided instruction class had low standard deviation indicating that the GeoGebra instructions positively affected all the students in the class. In a similar research study, Seloraji and Eu (2017) found that Geogebra integrated teaching enhanced students' performance in geometry in Malaysia. 
The effect of GeoGebra on the mathematics learning of underprivileged students with low mathematical ability was explored by Amam, Fatimah, Hartono and Effendi (2017) in Indonesia. The mathematics topic of the study was trigonometry. The study showed that GeoGebra positively impacted the students' mathematics learning achievement and motivation to learn mathematics.

In South Africa, Pfeiffer (2017) found that GeoGebra enhanced pre-degree students' understanding of functions and other mathematics topics. Mthethwa (2015) explored the effect of GeoGebra on students' learning of Euclidean geometry in some secondary schools in South Africa. The study found that the students enjoyed learning with GeoGebra and found the GeoGebra assisted learning motivating. Similarly, Godebo (2018) studied Grade 11 students' experiences and perceptions on GeoGebra in learning Euclidean geometry in some secondary schools in South Africa. The researcher found that GeoGebra enhanced students' understanding of Euclidean Geometry.

Some other studies (e.g. Bulut, Akçakın, Kaya, \& Akçakın, 2016; Jelatu, Sariyasa, \& Ardana, 2018; Mustafa, 2015; Zulnaidi, Oktavika \& Hidayat, 2020) show that GeoGebra is effective in enhancing students' learning of some mathematical concepts. On the contrary, a few studies found reported that GeoGebra did not have any significant effect on students' learning of some mathematical concepts when compared with the pencil and paper method. For example, Masri, Hiong, Tajudin, Zamzana and Shah (2016) in a study on the effects of GeoGebra integrated Teaching on Malaysian Secondary school students' performance of Circle III topic did not find any significant effect of teaching the GeoGebra.

In all, the literature discussed in this section, show strong evidence of the positive effect of GeoGebra on students' learning of many mathematics topics. Equally, the findings from the literature suggest that GeoGebra could have a significant effect on students' linear functions learning achievement in the South African context.

\section{Research Methodology}

\subsection{Research design and sample}

The study used a non-equivalent control group pre-test-post-test quasiexperimental design. Non-equivalence control group quasi-experimental design is a between-subjects design in which the experimental and control groups are not equated by randomisation (Cohen, Manion \& Morrison, 2011). The students who participated had not been randomly assigned to the classes; instead, intact classes were used to avoid disruption of classes.

The participants were 94 Grade 9 students from three underperforming schools. The schools are in rural communities in the same geographical area in a Province in South Africa. The students are from poor socio-economic backgrounds hence they do not pay school fees and they are provided with free meals at school by the government. The schools were purposively selected because of their record of persistent poor achievement in mathematics over the years. The sample comprised 31 students (15 girls and 16 boys) from school A, 
35 students (16 girls and 19 boys) from school B, and 28 students (16 girls and 12 boys) from school C. Schools A and C were the control groups while School B was the experimental group. School B was chosen as the experimental group because it had some computers that were donated to the school by an organisation. The computers were not used for teaching before the time of the study. The two control groups were used to ensure that the effects of any confounding variables are minimised because "two control groups can yield consistent and unbiased estimates of bounds on the treatment effect when conventional adjustments fail"' (Rosenbaum, 1987, p.297).

\subsection{Data collection instrument}

The instrument used for data collection was a linear functions achievement test. The test consisted of five questions with sub-questions that examined students' knowledge of drawing and interpreting linear functions. For example, draw the graph $y=2 x-1$ explored the students' ability to draw linear functions graphs. What is the y-intercept of $y=2 x-3$ ? explored the students' ability to interpret a representation of a linear functions. The test questions were developed by three mathematics teachers with over 5 years of teaching experience. The test served as the pre-test and the post-test.

The test was checked and validated by 2 mathematics education specialists (called mathematics subject advisers in the Department of Education). The validator adjudged the questions relevant for the study and at the appropriate cognitive levels. The reliability of the test was ascertained using data from a trial study conducted in another school. The reliability of the test was calculated using the Kuder-Richardson (KR-10) formula (McMillan \& Schumacher, 2013). An alpha value of 0.72 was obtained. This value indicates that the test was reliable (Fraenkel \& Wallen, 2009).

\subsection{Interventions}

The teaching in all the groups followed 10 one-hour lessons designated for teaching the topic. The lessons were taught by the teachers in their schools. The teachers used the Department of Basic Education worksheets in teaching the topic. The worksheets were issued to the teachers during cluster meetings where teachers in an area meet and plan lessons together. The teachers were all professionally qualified mathematics teachers and have had a minimum of 5 years of teaching experience. They have all been given basic training on GeoGebra by the curriculum adviser before this study.

The teaching in the control groups involved the traditional teacher explanations, followed by some examples on the chalkboard and giving of exercises. GeoGebra was not introduced to these students either before or during the intervention. In the experimental group, GeoGebra was used to teach the lessons. The students were introduced to GeoGebra in the first lesson. During the lessons, the teacher introduced the lesson, used GeoGebra to explain some of the concepts, and gave exercise to the students to work through using GeoGebra while the teacher monitors the students and helped them when they needed help or further explanations. The lessons in all the schools were taught following the lesson schedule provided by the Provincial Department of Basic 
Education. Hence, the same contents were covered in all the schools over the same period according to the lesson plan. After the data collection, the teachers in the control group schools were encouraged to introduce GeoGebra to their students.

\subsection{Data analysis}

Inferential statistics were used for data analyses. The tests scores were tested for normality using the Shapiro-Wilk test to establish whether the data were normally distributed and thus determine whether a parametric or nonparametric test should be carried out on the data. The results of the test of normality for both tests showed that the scores were not normally distributed $(\mathrm{p}<0.05)$. Hence, non-parametric tests (namely Kruskal-Wallis [KW] and MannWhitney U [MWU] comparison tests) were conducted.

\subsection{Ethical considerations}

Permission was obtained from the provincial education authority and the management of the schools before the commencement of the study. Also, informed consent was obtained from participants in writing before the study commenced. To ensure the confidentiality of the participants and the schools, the names of the schools and students are not mentioned anywhere in reporting the research.

\section{Findings}

The summary of the tests results is presented in Table 1 . The pre-test mean scores were 1.52, 2.11, and 1.61 for groups $\mathrm{A}, \mathrm{B}$, and $\mathrm{C}$ respectively. The overall post-test mean scores were $17.74,48.49$, and 18.43 for groups A, B, and C respectively. Besides, the groups' post-test mean scores were $8.12,42.65$, and 6.08 in drawing linear functions graphs, and 29.03, 57.51, and 32.92 in the interpretation of linear functions, for groups $\mathrm{A}, \mathrm{B}$ and $\mathrm{C}$ respectively.

Table 1: Descriptive statistics of the results of the tests

\begin{tabular}{lcccccc}
\hline & Group & N & Min & Max & Mean & Std. D \\
\hline Pre-test & A & 31 & 0.00 & 7.00 & 1.52 & 1.59 \\
(General) & B & 35 & 0.00 & 8.00 & 2.11 & 1.81 \\
\hline Post-test & C & 28 & 0.00 & 7.00 & 1.61 & 1.64 \\
(General) & $\mathrm{A}$ & 31 & 2.00 & 50.00 & 17.74 & 10.80 \\
\hline Post-test & $\mathrm{B}$ & 35 & 16.00 & 74.00 & 48.49 & 15.01 \\
Drawing graph & $\mathrm{C}$ & 28 & 6.00 & 50.00 & 18.43 & 11.13 \\
& $\mathrm{~A}$ & 31 & 0.00 & 55.56 & 8.12 & 15.95 \\
\hline Post-test & $\mathrm{B}$ & 35 & 0.00 & 81.48 & 42.65 & 24.21 \\
Interpretation & $\mathrm{C}$ & 28 & 0.00 & 40.74 & 6.08 & 10.49 \\
of linear & $\mathrm{A}$ & 31 & 0.00 & 65.22 & 29.03 & 15.16 \\
functions & $\mathrm{B}$ & 35 & 30.43 & 82.61 & 57.51 & 15.10 \\
\hline
\end{tabular}

To test for any statistically significant differences in the groups' tests scores, a non-parametric inferential statistics test namely the Kruskal-Wallis (KW) test was conducted. The non-parametric inferential statistics test was used because 
the students' tests scores in the three groups were not found to be normally distributed. The result of the KW test of the groups' pre-test scores is shown in Table 2.

Table 2: Result of the Kruskal-Wallis test of the pre-test scores

\begin{tabular}{lcc|lr}
\hline & Rank & & \multicolumn{2}{c}{ Test statistics } \\
\hline Group & N & Mean rank & & 3.339 \\
\hline A & 31 & 43.00 & Kruskal-Wallis H & 2 \\
B & 35 & 53.84 & df & .188 \\
C & 28 & 44.55 & Asymp. Sig. & \\
Total & 94 & & & \\
\hline
\end{tabular}

The KW test result shows that there was no statistically significant difference between any two groups $(\mathrm{H}(2)=3.339, \mathrm{p}>0.05)$ in the pre-test. Based on this, one might say that mean pre-test scores of the students in all the groups were similar. Hence, the three groups were of comparable ability in drawing and interpreting linear functions before the treatment.

The descriptive statistics of the post-test results (Table 1) show that group B (the experimental group) had the highest mean score among the three groups in the post-test (in general and in drawing and interpreting linear functions). The interest of this paper was on the effectiveness of GeoGebra on the students' drawing linear functions graphs and interpreting linear functions. Accordingly, further analyses of the post-test results were carried out.

\subsection{Drawing linear graphs}

The KW test result of the groups in drawing graphs of linear functions (Table 3) shows mean ranks of $34.18,70.20$, and 33.88 for groups $\mathrm{A}, \mathrm{B}$, and $\mathrm{C}$ respectively.

Table 3: KW Test result - Drawing Linear Functions Graphs

\begin{tabular}{lrc|lr}
\hline & Rank & & \multicolumn{2}{|c}{ Test statistics } \\
\hline School & $\mathbf{N}$ & Mean rank & & 43.072 \\
A & 31 & 34.18 & Kruskal-Wallis H & 2 \\
B & 35 & 70.20 & df & .000 \\
C & 28 & 33.88 & Asymp. Sig. & \\
Total & 94 & & & \\
\hline
\end{tabular}

The KW test result $(\mathrm{H}(2)=43.07, \mathrm{p}<0.001)$, shows that a statistically significant difference exits between the mean ranks of at least two groups in drawing linear functions graphs. Therefore, a post-hoc analysis (MWU test) was run to check where the differences existed in groups.

MWU test descriptive statistics (Table 4) show that in all cases, the mean rank of group B (the experimental group) was higher than the mean ranks of Groups A and $C$ (the control groups) in drawing linear functions graphs. 
Table 4: The MWU test result - drawing Linear Functions Graphs

\begin{tabular}{lccrlr}
\hline \multicolumn{2}{c}{ Ranks } & & \multicolumn{2}{c}{ Test statistics } \\
\hline Group & N & $\begin{array}{c}\text { Mean } \\
\text { rank }\end{array}$ & $\begin{array}{c}\text { Sum of } \\
\text { ranks }\end{array}$ & & \\
\hline A & 31 & 29.74 & 922.00 & Mann-Whitney U & 426.000 \\
C & 28 & 30.29 & 848.00 & Wilcoxon W & 922.000 \\
Total & 59 & & & Z & -.146 \\
& & & & Asymp. Sig. (1-tailed) & .884 \\
\hline A & 31 & 20.44 & 633.50 & Mann-Whitney U & 137.500 \\
B & 35 & 45.07 & 1577.50 & Wilcoxon W & 633.500 \\
Total & 66 & & & Z & -5.375 \\
& & & & Asymp. Sig. (1-tailed) & .000 \\
\hline C & 28 & 18.09 & 506.50 & Mann-Whitney U & 100.500 \\
B & 35 & 43.13 & 1509.50 & Wilcoxon W & 506.500 \\
Total & 63 & & & Z & -5.511 \\
& & & & Asymp. Sig. (1-tailed) & .000 \\
\hline
\end{tabular}

The test Statistics between Groups A and C (the control groups) show that no statistically significant difference existed between their achievements scores ( $\mathrm{U}=$ 426, $p>0.05$ ). However, the test Statistics between Groups A and B shows that the achievement of Group B was statistically significantly higher than the achievement of Group A $(\mathrm{U}=138, \mathrm{p}<0.05, \mathrm{r}=.66)$. Similarly, the test Statistics between Groups B and C shows that the achievement of Group B was statistically significantly higher than the achievement of Group C $(U=101, p<$ $0.05, r=.69$ ). Based on these, the hypothesis that GeoGebra assisted linear functions instruction does not significantly affect Grade 9 students' learning achievement in the drawing of linear functions graphs was rejected. Hence, it was concluded that GeoGebra assisted linear functions instruction significantly affected the Grade 9 students' learning achievement in drawing of linear functions graphs. Moreover, the effect sizes (0.66 and 0.69) indicate that the differences between the experimental group and the control groups were large (Cohen 1988).

\subsection{Interpreting linear functions}

The KW test of the groups' achievement scores on the interpretation of the linear functions (Table 5) shows mean ranks of 31.87, 70.66, and 36.62 for groups A, B, and $C$ respectively.

Table 5: KW Test result - Interpreting Linear Functions

\begin{tabular}{lrr|lr}
\hline \multicolumn{3}{c|}{ Rank statistics } & \multicolumn{2}{c}{ Test statistics } \\
\hline School & $\mathrm{N}$ & Mean rank & & 40.909 \\
A & 31 & 31.53 & Kruskal-Wallis H & 2 \\
B & 35 & 70.66 & df & .000 \\
C & 28 & 36.23 & Asymp. Sig. & \\
Total & 94 & & & \\
\hline
\end{tabular}

The KW test statistics provide very strong evidence of a difference between the mean rank of at least two groups in the interpretation of linear functions $(\mathrm{H}(2)=$ $40.91, \mathrm{p}<.05)$. To ascertain where the differences existed in groups, a post-hoc 
analysis using the MWU test was carried out. The result (Table 6) shows that group B (GeoGebra group) achieved above each of the non- GeoGebra groups.

Table 6: MWU Test result - in Interpreting Linear Functions

\begin{tabular}{lccrlr}
\hline & \multicolumn{2}{c}{ Ranks } & \multicolumn{2}{c}{ Test statistics } \\
\hline Group & $\mathrm{N}$ & $\begin{array}{c}\text { Mean } \\
\text { rank }\end{array}$ & $\begin{array}{c}\text { Sum of } \\
\text { ranks }\end{array}$ & & \\
\hline A & 31 & 28.24 & 875.50 & Mann-Whitney U & 379.500 \\
C & 28 & 31.95 & 894.50 & Wilcoxon W & 875.500 \\
Total & 59 & & & Z & -.833 \\
& & & & Asymp. Sig. (1-tailed) & .405 \\
\hline A & 31 & 19.29 & 598.00 & Mann-Whitney U & 102.000 \\
B & 35 & 46.09 & 1613.00 & Wilcoxon W & 598.000 \\
Total & 66 & & & Z & -5.678 \\
& & & & Asymp. Sig. (1-tailed) & .000 \\
C & 28 & 18.79 & 526.00 & Mann-Whitney U & 120.000 \\
B & 35 & 42.57 & 1490.00 & Wilcoxon W & 526.000 \\
Total & 63 & & & Z & -5.141 \\
& & & & Asymp. Sig. (1-tailed) & .000 \\
\hline
\end{tabular}

The test Statistics between the control groups (A and C) show that no statistically significant difference existed between their achievements scores $(\mathrm{U}=$ 379.5, $\mathrm{p}>0.05)$. Nevertheless, the test Statistics between Groups A and B show that the achievement of Group B was statistically significantly higher than the achievement of Group A ( $(\mathrm{U}=102, \mathrm{p}<0.05, \mathrm{r}=.70)$. Equally, the test Statistics between Groups B and C shows that the achievement of Group B was statistically significantly higher than the achievement of Group C $(U=120, p<$ $0.05, r=.65$ ). Based on these results, the hypothesis that GeoGebra assisted linear functions instruction does not significantly affect Grade 9 students' learning achievement in interpreting linear functions was rejected. GeoGebra assisted linear functions instruction significantly affected the Grade 9 students' learning achievement in interpreting of linear functions. The effect sizes of 0.65 and 0.70 indicate that the differences between the Geogebra group and the control groups were large.

\section{Discussion}

This study explored the effectiveness of GeoGebra assisted instruction on Grade 9 students' learning achievement in drawing and interpreting linear graphs. The results showed that the students taught via GeoGebra assisted instruction, significantly achievement better than the control groups students in drawing and interpreting linear functions. The result appears to corroborate the findings of several previous studies (e.g. Kushwaha, Chaurasia \& Singhal, 2014; Seloraji \& Eu, 2017; Praveen \& Leong, 2013; Rahman \& Puteh, 2017). In particular, the finding of this study agrees with the findings of some other research studies in South Africa (for example, Godebo, 2018; Pfeiffer, 2017;), that GeoGebra has a significant positive effect on students' learning achievement in some mathematics concepts.

The positive effect of GeoGebra on students learning achievement found in this study could be because the interactive nature of GeoGebra (Hohenwarter \& 
Jones, 2007) enabled the students in the GeoGebra assisted instruction to thoroughly explore and grasp linear functions better than the students in the control groups. Moreover, GeoGebra makes it easy for one to accurately draw graphs. Correctly drawn graphs enhance visualisation, understanding, and interpretation. Zulnaidi, Oktavika and Hidayat (2020) noted that "GeoGebra can illustrate mathematical concepts and procedures well through visuals and graphs, which considerably aid students in mastering and understanding concepts and procedures pertaining to functions" (p.1). In contrast, drawing graphs manually is prone to error and makes it difficult for one to understand and interpret the graphs accurately. So, accurately drawing of the graphs using GeoGebra could have helped the students in the GeoGebra assisted class to learn better than their counterparts did not learn using Geogebra.

Another factor that the findings of this study might be attributed to is the younger generations' love for technology (Bester \& Brand, 2013). In all possibility, students in the experimental group might have enjoyed their learning of linear function more than the students in the control groups. Students' enjoyment of technology-assisted instructions has been observed in other studies to lead to more student engagement with the subject content and consequently higher achievement outcomes (Mthethwa, 2015, Ogbonnaya, 2010; Thambi \& Eu, 2012).

\section{Conclusion and Recommendations}

The study found that GeoGebra assisted instruction had significantly affected 9th Graders learning achievement in linear graphs and interpretations of linear functions. The findings suggest that GeoGebra assisted mathematics instruction has the potential to enhance students' achievement in linear functions. Hence, GeoGebra assisted mathematics instruction might contribute to improved students' mathematics learning and consequently the technological and socioeconomic development of the country. We, therefore, recommend more research studies on the efficacy of technology-assisted instruction on students' learning of linear functions and other mathematics concepts.

The study adds to the evidence suggesting that the use of technology, and in particular GeoGebra, in teaching some topics in mathematics might result in higher levels of student achievement than the traditional 'chalk-and-talk' method. We recommend that teachers explore the effectiveness of integrating GeoGebra and other information and communication technologies with their teaching of mathematical topics in general.

We also recommend that the Department of Basic Education and all other stakeholders in mathematics education in the country should encourage teachers to integrate GeoGebra in mathematics teaching. When teachers begin to use GeoGebra in teaching it will likely encourage students to learn mathematics by themselves. The concomitant effect would be improved student learning as desired by the Government and all stakeholders in mathematics education in the country. 
Many schools in the country do not have ICT facilities to enable the use of GeoGebra or any computer-based technology in teaching. Hence, we recommend the provision of ICT facilities in all the schools in the country so that teachers and students will be able to use Geogebra for mathematics teaching and learning.

Furthermore, we recommend that mathematics teachers be offered the relevant professional development workshops to acquaint them with the affordances of GeoGebra for mathematics teaching. This will likely enhance their knowledge and dispositions towards the use of GeoGebra in teaching.

\section{References}

Akcay, A. O. (2017). Instructional Technologies and Pre-Service Mathematics Teachers' Selection of Technology. Journal of Education and Practice, 8(7), 163-173.

Alkhateeb, M. A., \& Al-Duwairi, A. M. (2019). The Effect of Using Mobile Applications (GeoGebra and Sketchpad) on the Students' Achievement. International Electronic Journal of Mathematics Education, 14(3), 523-533. https://doi.org/10.29333/iejme/5754

Amam, A., Fatimah, A. T., Hartono, W., \& Effendi, A. (2017). Mathematical Understanding of the Underprivileged Students through GeoGebra. Journal of Physics: Conf. Series, 895 012007, 1-2. https://doi.org/10.1088/17426596/895/1/012007

Arbain, N., \& Shukor, N. A (2015). The effects of GeoGebra on students' achievement. Procedia - Social and Behavioral Sciences, 172, 208-214. https://doi.org/10.1016/j.sbspro.2015.01.356

Aydos, M. (2015). The impact of teaching mathematics with GeoGebra on the conceptual understanding of limits and continuity: the case of Turkish gifted and talented students (Master's thesis). İhsan Doğramacı Bilkent University, Ankara, Turkey.

Bester, G., \& Brand, L. (2013). The effect of using technology on learner attention and achievement in the classroom. South African Journal of Education, 33(2), 1-15.

Bray, A., \& Tangney, B. (2017). Technology usage in mathematics education research - A systematic review of recent trends. Computers and Education, 114, 255-273. https://doi.org/10.1016/j.compedu.2017.07.004

Bulut, M., Akçakın, H. U., Kaya, G., \& Akçakın, V. (2016). The effects of GeoGebra on third grade primary students' academic achievement in fractions. International Electronic Journal of Mathematics Education, 11(2), 347-355. https://doi.org/10.12973/iser.2016.2109a

Cohen, J. (1988). Statistical power analysis for the behavioral sciences. New York: Routledge Academic.

Cohen, L., Manion, L., \& Morrison, K. (2011). Research Methods in Education (7th ed.) New York: Routledge

Department of Basic Education. (2011). Curriculum Assessment Policy Statement Grades 7-9. Pretoria: Government Printer.

Disbudak, O., \& Akyuz, D. (2019). The Comparative Effects of Concrete Manipulatives and Dynamic Software on the Geometry Achievement of Fifth-Grade Students. International Journal of Technology in Mathematics Education, 26 (1), 3-20. https://doi.org/10.1564/tme_v26.1.01

Fraenkel, J. R., \& Wallen, N. E. (2009). How to Design Evaluate Research in Education (7th ed). New York: McGrawHill Companies. 
Godebo, G. H. (2018). Application of GeoGebra on Euclidean geometry in rural high schools: Grade 11 learners (Master's dissertation). University of Zululand, South Africa.

Granberg, C., \& Olsson, J. (2015). ICT-supported problem solving and collaborative creative reasoning: Exploring linear functions using dynamic mathematics software. Journal of Mathematical Behavior, 37, 48-62. https://doi.org/10.1016/j.jmathb.2014.11.001

Hohenwarter, M., \& Jones, K. (2007). Ways of linking geometry and algebra: The case of GeoGebr. Proceedings of British Society for Research into Learning Mathematics, 27 (3), 126-131.

Hohenwarter, M., \& Lavicza, Z. (2009). The strength of the community: how GeoGebra can inspire technology integration in mathematics teaching. MSOR Connections, 9(2), 3-5.

Jelatu, S., Sariyasa, \& Ardana, I. M. (2018). Effect of GeoGebra-Aided REACT Strategy on Understanding of Geometry Concepts. International Journal of Instruction, 11(4), 325-336. https://doi.org/10.12973/iji.2018.11421a

Khalil, M., Farooq, R. A., Çakıroğlu, E., Khalil, U., \& Khan, D. M. (2018). The Development of Mathematical Achievement in Analytic Geometry of Grade-12 Students through GeoGebra Activities. Eurasia Journal of Mathematics, Science and Technology Education, 14(4), 1453-1463. https://doi.org/10.29333/ejmste/83681

Laridon, P., Barnes, H., Kitto, A., Myburg, M., Pike, M., Scheiber, J., Sigabi M., \& Wilson, H. (2004). Classroom mathematics: Grade 10 learners' book. Sandton: Heinemann.

Masri, R., Hiong, T. S., Tajudin, N. M., Zamzana, Z. Z., \& Shah, R. L. Z. (2016). The effects of using GeoGebra teaching strategy in Malaysian secondary schools: A case study from Sibu, Sarawak. Malaysian Journal of Society and Space, 12(7), 13-25.

McMillan, J., \& Schumacher, S. (2013). Research in education: Evidence-based inquiry, New York: Pearson.

Mthethwa, M. Z. (2015). Application of GeoGebra on Euclidean geometry in rural high schools: Grade 11 learners (Master's dissertation). University of Zululand, South Africa.

Mueller, J., Wood, E., Willoughby, T., Ross, C., \& Specht, J. (2008). Identifying discriminating variables between teachers who fully integrate computers and teachers with limited integration. Computers \& Education, 51(4), 1523-1537.

Mustafa, A. (2015). The impact of teaching mathematics with GeoGebra on the conceptual understanding of limits and continuity: The case of Turkish gifted and talented students, (Master's dissertation). İhsan Doğramacı Bilkent University, Turkey.

Ogbonnaya, U. I. (2010). Improving the teaching and learning of parabolic functions by the use of information and communication technology. African Journal of Research in Mathematics, Science and Technology Education, 14(1), 49-60.

Ogbonnaya, U. I., \& Mji, A. (2012). Enhancing students' learning of hyperbolic functions by the use of information and communication technology. Proceedings of 5th Annual International Conference on Education and New Learning Technologies (Edulearn), Barcelona, Spain, 5619-5216.

Pfeiffer, C. (2017). A study of the development of mathematical knowledge in a GeoGebra focused learning environment (Doctoral thesis). Stellenbosch University, Stellenbosch.

Pierce, R. (2005). Linear functions and the triple influence of teaching on the development of students' algebraic expectations, Proceedings of the 19th Conference of the International Group for the Psychology of Mathematics Education, Melbourne, Australia, 4, 81-88.

Pjanić, K., \& Lidan, E. (2015). One Usage of Geogebra in Enhancing Pre-service Mathematics Teachers' Content Knowledge. Turkish Journal of Computer and Mathematics Education, 6(1), 18-30. https://doi.org/10.16949/turcomat.78085 
Phan-Yamad, T., \& Man, S. W. (2018). Teaching statistics with GeoGebra. North American GeoGebra Journal, 7(1), 14-24

Praveen, S., \& Leong, K. (2013). Effectiveness of using GeoGebra on students' understanding of circles. The Malaysian Online Journal of Educational Technology, 1(4), 1-11.

Rahman, M. H. A., \& Puteh, M. (2017). Learning trigonometry using GeoGebra learning module: Are underachiever pupils motivated? Sains humanika, 9(1-2), 39-42. https://doi.org/10.11113/sh.v9n1-2.1095

Rosenbaum, P. R. (1987). The role of a second control group in an observational study. Statistical Science, 2(3), 292-306.

Kushwaha, R. C., Chaurasia, P. K., \& Singhal, A. (2014). Impact on students' achievement in teaching mathematics using GeoGebra, Proceedings of IEEE Sixth International Conference on Technology for Education, Amrita University, 34-137.

Richardson, V. (2003). Constructivist pedagogy. Teachers College Record, 105(9), 1623-1640.

Slavin, R. E., \& Davis N. (2006). Educational Psychology: Theory and Practice. East Montpelier: Johnson State College.

Seloraji, P., \& Eu, L. K. (2017). Students' performance in geometrical reflection using GeoGebra. Malaysian Online Journal of Educational Technology, 5(1), 65-77. https://doi.org/10.17220/mojet

Takači, D., Stankov, G., \& Milanovic, I. (2015). Efficiency of learning environment using GeoGebra when calculus contents are learned in collaborative groups. Computers and Education, 82, 421-431. https://doi.org/10.1016/j.compedu.2014.12.002

Takači, D., \& Vukobratović, R. (2011). On the role of GeoGebra in examining functions. Proceedings of the International GeoGebra Conference for Southeast Europe, Novi Sad-Serbia, 53-60.

Thambi, N., \& Eu, L. K. (2012). Effect of students' achievement in fractions using GeoGebra. SAINSAB, 16, 97-106.

Wassie, Y. A., \& Zergaw, G. A. (2018). Capabilities and Contributions of the Dynamic Math Software, GeoGebra-A review. North American GeoGebra Journal, 7(1), 6886.

Wijayanti, D. (2018). Two notions of 'linear function' in lower secondary school and missed opportunities for students' first meeting with functions. The Mathematics Enthusiast, 15(3), 467-481.

Zengin, Y., Furkanb, H., \& Kutluca, T. (2012). The effect of dynamic mathematics software GeoGebra on student achievement in teaching of trigonometry. Procedia - Social and Behavioral Sciences, 31, 183-187. https://doi.org/10.1016/j.sbspro.2011.12.038

Zulnaidi, H., Oktavika, E., \& Hidayat, R. (2020). Effect of use of GeoGebra on achievement of high school mathematics students. Education and Information Technologies, 25(1), 51-72. https://doi.org/10.1007/s10639-019-09899-y 